\title{
Mortality Projection on Indonesia's Abridged Life Table to Determine the EPV of Term Annuity
}

\author{
Galuh Oktavia Siswono1*, Ulil Azmi ${ }^{2}$, Wawan Hafid Syaifudin ${ }^{3}$ \\ ${ }^{1}$ Aktuaria Departemen, Institut Teknologi Sepuluh Nopember, Surabaya, Indonesia, e-mail : \\ galuhoktavias@gmail.com \\ ${ }^{2}$ Aktuaria Departemen, Institut Teknologi Sepuluh Nopember, Surabaya, Indonesia, e-mail : \\ ulilazmi0211@gmail.com \\ ${ }^{3}$ Aktuaria Departemen, Institut Teknologi Sepuluh Nopember, Surabaya, Indonesia, e-mail : \\ wawan.hafid@gmail.com
}

\section{Article history:}

Received : 27-02-2021

Reviced : 02-04-2021

Accepted : 05-04-2021

\section{Keyword:}

Mortality projection;

Abridged life table;

Term Annuity

\section{ABSTRACT}

The life insurance industries usually use the Life Table for the valuation process, especially in calculating premiums and policy values of a policy. However, the Life Table is rarely updated; and it may even take years before they are updated. This happens because the insurers believe that the information in the Life Table is still related to the current state of a country and for the next several years. In fact, data and information related to mortality rates in a country are constantly changing and always being updated annually. Therefore, as an approach, researchers use the projection of mortality to approach the mortality rate in the future. Thus, future mortality data can be predicted so that better policies can be made by the governments or insurance industries. In this study, the Abridged Life Table of Indonesia is used in the projection of mortality for both sexes (male and female) of the population in Indonesia. The results of mortality projection are then used to calculate the Expected Present Value (EPV) of a term annuity-due under uniform distribution of deaths (UDD) for several values of $n$ and ages. The results obtained show that there is a decrease in the value of the mortality rate in the next few years. Therefore, it can be assumed that there is a possibility for longevity risk to occur in the future.

This is an open access article under the CC BY-SA license.

DOI: https://doi.org/10.30812/varian.v4i2.1094

\section{A. INTRODUCTION}

In actuarial science, mortality and longevity risk play an important role in calculating premiums and reserve benefits. If the calculation of premiums or benefits reserves is inaccurate, the company will potentially experience losses and be unable to fulfill their liabilities to pay benefits in the future. Further, the information related to the population dynamics and mortality rates of a country could also help the government to make a better and more effective policy in the future (Coloma \& Date, 2020).

In 2019, the Indonesian Life Insurance Association (AAJI) has released the Indonesian Mortality Table IV (TMIV). TMIV is a mortality table that contains the probability of death for individuals aged 0-110 years. However, the data used in TMIV is the population of people who have been insured (AAJI, 2019). If the government wants to take the best policy by using the mortality rate of the Indonesian population in the future, then demographic data would be a better data used to find out information about the current condition of the Indonesian population. This is based on the possibility of a decrease in the probability of annual death in adulthood that may occur in the future (Zhu et al., 2018). Thus, it is necessary to observe mortality rate data for the entire population in Indonesia and carry out mortality projections to measure the longevity risk (Chang \& Sherris, 2018). 
Mortality projection is a method that often used by the researchers to make a prediction as far as possible from the trend of mortality so that it can be used statisticaly in the future. By projecting the mortality, especially the mortality rates in Indonesia, the government or insurance company could predict and minimize the possible losses caused by the longevity risk. (Janssen, 2018).

This study uses Indonesian mortality data obtained from the World Health Organization (WHO) website. The data obtained is in the form of Abridged Life Table which contains information of ${ }_{n} q_{x}$, the probability of a person age $x$ dies in age $x+n$, from 2000 to 2019. These data would be projected using a simple forecasting method, Double Exponential Smoothing. Then the projection results would be used to create an Abridged Life Table for the next 5 years period (Ibrahim \& Siri, 2011). The Abridged Life Table obtained was used to analyze the distribution of life expectancy and the determination of the value of the term annuity using the assumption of a uniform distribution of death (UDD) for several age cases in both groups of women and men in Indonesia.

A consideration for using UDD assumption to evaluate the EPV of annuity-due is that the UDD offers a reasonable estimate. In addition, in practice, the third term on the Woolhouse's method is often omitted. This condition results in the value of the Woolhouse methods similar with the results produced by UDD approach (Dickson, D., Hardy, M., \& Waters, 2009). The UDD assumption are often used as solutions to get annuities with more frequent payments. This will help in measuring the value of the annual term EPV using data on Indonesia's Abridged Life Table. In addition, by getting an annuity that is closer to the actual situation, industry and government can minimize the possible risks in future policy making (Diaz et al., 2018).

\section{B. LITERATURE REVIEW}

The concept of life insurance and life annuities has been known and developed since the 18th century, where the management of insurance company assets and liabilities is based on the death rate of the policyholder each year (Burch, 2018). However, the mortality rate used in calculations is generally obtained from calculations using a life table. The Life Table was first created by John Graunt and Edmund Halley, where it summarizes a survival model detailing the proportion of souls that are expected to survive to a certain age. Life tables are very helpful in life insurance companies, especially in valuation of the premiums (Pavlov \& Mihova, 2018). Premium is an amount of money paid by someone who buys an insurance policy, also known as a policy holder, as a substitute for taking a risk by the insurer (the insurance company). In life insurance, the benefits paid are related to a person's future life (Bacinello et al., 2021). If the death of the policy holder occurs while the contract is still running (in force), the insurance company as the protection provider will pay the benefits to the policyholder or their beneficiary. Where benefit payments can be in the form of an annuity (routine payment) or payment of a full amount of money (single premium)(Li et al., 2015).

The concept of an annuity is a slightly different from insurance. Annuities could be broadly divided into two, namely a definite annuity and an annuity of the soul. General annuity is an annuity that provides payments without certain conditions. While a life annuity is an annuity that is sold by a life insurance company whose benefit payments depend on the life and death of the policy holder, be it an annuity payment until the policyholder dies (whole life annuity) or an annuity payment up to a certain period (term life annuity). Annuity in life insurance could also be present as the premium paid by the policyholders. Hence, the insurance company could use life annuity to calculate the premiums charged for the policyholder or the policy value of an insurance policy (Dickson, D., Hardy, M., \& Waters, 2009).

The calculation of annuities in the concept of life insurance and life annuities plays an important role, especially in calculating premiums, benefit reserves, and benefits in pension funds. The Present Value of a life annuity is a random variable whose value depends on the life span of a person, particularly the policyholder, in the future (Dmitriev, Y. G., Gubina, O. V, \& Koshkin, 2019).

In this research we will consider to calculate the EPV of the term-life annuity due. Supposed that there is an annuity which pays 1 unit of money per year to a person currently aged $x$ for $n$ years. Then, the payments 
would be made at time as long as the policyholder's alive. Assuming the policyholder is still alive until age of $x+k$, then the payment would take a place at $t=0,1,2, \ldots, n-1$. If we denote that the present value of this annuity by $Y$, then we obtain (Koshkin \& Gubina, 2016)

and

$$
Y=\left\{\begin{array}{cl}
\ddot{a}_{\overline{K_{x}+1 \mid}} & ; \text { if } K_{x}=0,1, \ldots, n-1 \\
\ddot{a}_{\overline{n \mid}} & \text {;if } K_{x} \geq n
\end{array}\right.
$$

$$
Y=\ddot{a}_{\min \left(K_{x}+1, n\right) \mid}=\frac{1-v^{\min \left(K_{x}+1, n\right)}}{d}
$$

where $K_{x}$ is curtate future lifetime and $d$ is the annual effective discount rate.

The Expected Present Value of this annuity-due is denoted by $\ddot{a}_{x: \bar{n} \mid}$ which satisfies:

$$
\ddot{a}_{x: \bar{n} \mid}=\sum_{t=0}^{n-1} v^{t}{ }_{t} p_{x}
$$

where $v=\left(\frac{1}{1+i}\right)$ represents the discount factor and $t p_{x}$ is the probability of a person aged $x$ still alive until $x+t$.

The illustration of a $n$ year term-life annuity due payable 1 unit every year can be seen in the following diagram.

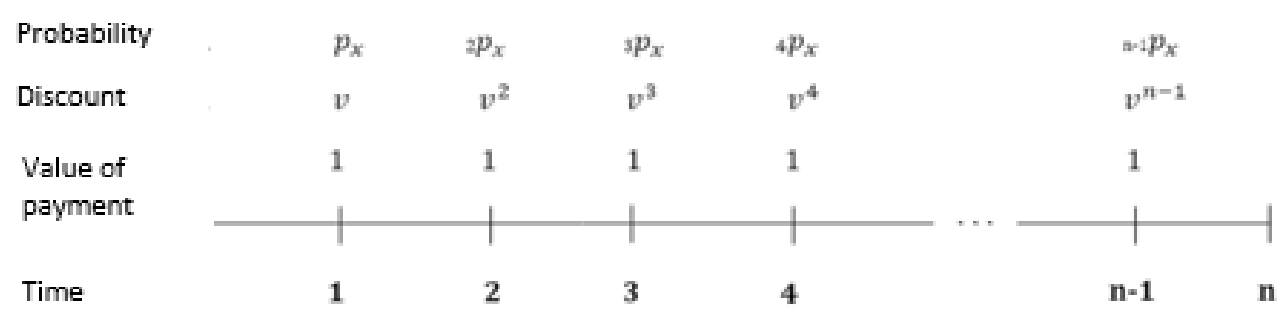

Figure 1. Timeline of $n$ Year Term-Life Annuity Due

Regarding to figure 1, it can be seen that a $n$ year term-life annuity due has a first payment at $t=0$ and the last payment at $t=n-1$. In addition, the payments made based on the the probabilties of life of a person at payment period. Therefore, the Expected Present Value (EPV) of $n$ year term-life annuity can be expressed as:

$$
\ddot{a}_{x: \bar{n} \mid}=1+v p_{x}+v^{2}{ }_{2} p_{x}+\cdots+v^{n-1}{ }_{n-1} p_{x}
$$

We apply the UDD assumption since there was a limited data and information of Indonesian Abridged Life Table. In this assumption, we apply the formula:

$$
\begin{aligned}
\ddot{a}_{x: \bar{n} \mid}^{(m)} & =\ddot{a}_{x}^{(m)}-v^{n}{ }_{\mathrm{n}} p_{x} \ddot{a}_{x+n}^{(m)} \\
& =\alpha(m) \ddot{a}_{x}-\beta(m)-v^{n}{ }_{\mathrm{n}} p_{x}\left(\alpha(m) \ddot{a}_{x+n}-\beta(m)\right) \\
& =\alpha(m)\left(\ddot{a}_{x}-v^{n}{ }_{\mathrm{n}} p_{x} \ddot{a}_{x+n}\right)-\beta(m)\left(1-v^{n}{ }_{\mathrm{n}} p_{x}\right) \\
& =\alpha(m) \ddot{a}_{x+\bar{n} \mid}-\beta(m)\left(1-v^{n}{ }_{\mathrm{n}} p_{x}\right)
\end{aligned}
$$

where:

$i \quad=$ annual effective interest rate

$\ddot{a}_{x: \bar{n} \mid}^{(m)}=$ EPV of $n$ year term-life annuity due payable $m$ times in a year

$\ddot{a}_{x}^{(m)}=$ EPV of whole-life annuity due payable $m$ times in a year

$\alpha(m)=\frac{i d}{i^{(m)} d^{(m)}}$

$\beta(m)=\frac{i-i^{(m)}}{i^{(m)} d^{(m)}}$ 


$$
\begin{array}{cl}
d & =\text { annual effective discount rate } \\
i^{(m)} & =\text { nominal interest rate convertible } m-\text { thly per year } \\
d^{(m)} & =\text { nominal discount rate convertible } m-\text { thly per year }
\end{array}
$$

Note that $\alpha(m)$ and $\beta(m)$ depend only on the value and frequency of payments. (Dickson, D., Hardy, M., \& Waters, 2009).

\section{RESEARCH METHODS}

In this research, we used the World health observation data obtained from World Health Organization (WHO). We limited the data for Indonesian's population only. However, we noted that the provided data was incomplete. The existing Life Table was not a complete life table, instead an Abridged Life Table. As an addition, the available information was a 5-year period data, started from 2000 to 2019. Thus, in order to complete the missing data, for example the data between 2000 and 2005, we used the linear interpolation method. Subsequently, we also projected the next 5-year data, namely for 2020, 2021, 2022, 2023, and 2024, by using Minitab-18 software and the Double Exponential Smoothing method.

There are several steps that we performed in this study. First, we used the projected data of the probability of death for Indonesian population. Following that, we calculated the Expected Present Value (EPV) of an annuity-due by using the projected data. Once obtaining the EPV of the annuity, we analyze the the effect of the longevity risk on male and female Indonesian's population by considering the differences in the EPV for different age groups as well as different payment periods. It is important to note that we used the data of policyholders aged 15, 35, and 65 in calculating the EPV of the annuity.

\section{RESULT AND DISCUSSION}

In this study, we tried to identify the effect of the projection of Indonesia's mortality probability on the EPV value of annual life annuities. According to the data of the chances of death for the Indonesian population by sex which was collected from the WHO website, we observed that there was a decline in mortality rates and an increase trend in mortality rates for several age groups. Figure 2 illustrates the graph of mortality rates for women and men in Indonesia, respectively.

With regards to Figure 2, it can clearly be seen that the mortality rate of Indonesian's population had decreased every year. It could be the case, since there was an improvement in the nutritional intake and a program from the government in reducing the mortality rates in Indonesia. However, the reduction in mortality rates means that there will be a growth in the number of ageing population in Indonesia for the next few years. As a consequence, there will be another type of risk faced by the government, that is a longevity risk. Thus, it is necessary to project future mortality to analyze and reduce the impact of longevity risk on future premium calculations. Focusing on the graph, one can see that the mortality rate was relatively high at an early age (for infants and children), then decreased until the age of 10-14 years. Following that, the mortality rate rose significantly with the age. In the data of this study, it is assumed that the probability of death over 85 years old is 1 , which means that no one will survive after the age of 85 years. 




(a)

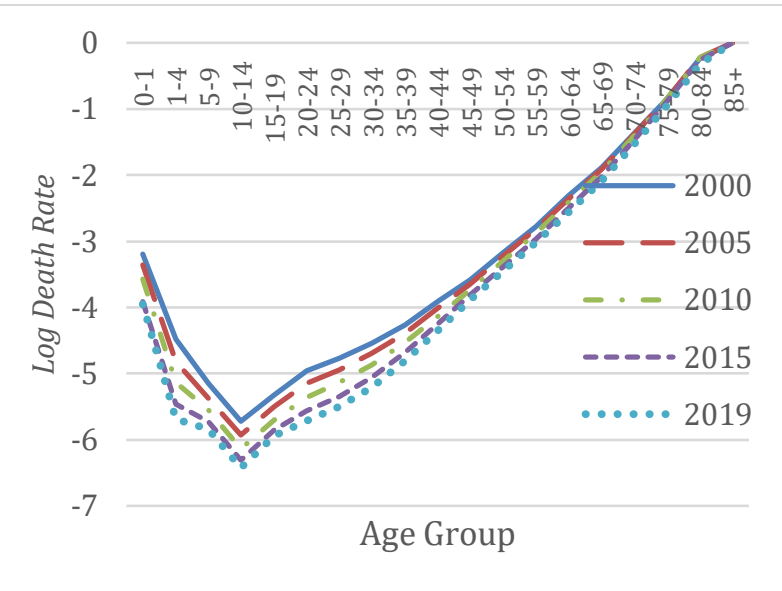

(b)

Figure 2. Mortality Rates of Indonesian Population for (a) Male and (b) Female

Table 1 shows the projections on the probability of death (denoted by ${ }_{n} q_{x}$ ) for the next 5 years, started in 2020. All these values indicate the probability of a person living at the beginning of the age interval, then dying during the interval of $(x, x+n)$. It can be seen, from table 1 , that there will be a decrease in the probability of death of men and women in some age groups. It is noticeable that we use this data to obtain the Abridged Life Table in the projection years which will later be used for the calculation of the EPV of term-life annuity due.

Table 1. Projections on the Probability of Death $\left(n q_{x}\right)$ of Indonesian Population Aged 15-19, 35-39, and 65-69

\begin{tabular}{ccccccc}
\hline \multirow{2}{*}{ Year } & \multicolumn{2}{c}{ Age 15-19 } & \multicolumn{2}{c}{ Age 35-39 } & \multicolumn{2}{c}{ Age 65-69 } \\
\cline { 2 - 7 } & Male & Female & Male & Female & Male & Female \\
\hline 2020 & 0.005239 & 0.002579 & 0.01023 & 0.007892 & 0.162035 & 0.109608 \\
\hline 2021 & 0.005217 & 0.002518 & 0.009969 & 0.007628 & 0.161045 & 0.108062 \\
\hline 2022 & 0.005195 & 0.002457 & 0.009709 & 0.007364 & 0.160054 & 0.106516 \\
\hline 2023 & 0.005174 & 0.002397 & 0.009448 & 0.0071 & 0.159064 & 0.10497 \\
\hline 2024 & 0.005152 & 0.002336 & 0.009188 & 0.006837 & 0.158074 & 0.103423 \\
\hline
\end{tabular}

In calculating the EPV of the annuity using the Abridged Life Table, the obtained data is not the exact age for each year group, instead the data for the initial age in each age group. At the beginning of the calculation, it was assumed that the EPV of the term-life annuity was calculated for the payment made every 5-year period. However, in order to obtain the EPV of annual term-life annuity, we use the UDD assumption to do the calculations.

It is important to note that we used several assumptions in calculating the EPV of annual term-life annuity. First, the distribution of deaths in each payment period is assumed to be UDD (uniform distribution of death). Second, the amount of payments made at every beginning of the year is 1 unit. Third, the value of the EPV of the annuity will be calculated separately for each age group in the Table 1. Last, the 5-year effective rate of return is assumed to be $5 \%$ in all calculations.

In the first case, we calculated the EPV of a term-life annuity payable 1 unit at every beginning of the year where $n=10$-year period for people aged 15,35 , and 65 , respectively. The results of this calculation by using the UDD assumption can be seen on Table 2 . 
Table 2. EPV of Term Life Annuity Paid 1 at Every Beginning of the Year $\left(\ddot{a}_{x: \bar{n}}\right)$ with $n=10$

\begin{tabular}{ccccccc}
\hline \multirow{2}{*}{ Year } & \multicolumn{6}{c}{$\ddot{\boldsymbol{a}}_{\boldsymbol{x}: \bar{n} \mid}$} \\
\cline { 2 - 7 } & \multicolumn{2}{c}{$\boldsymbol{x}=\mathbf{1 5}$} & \multicolumn{2}{c}{$\boldsymbol{x}=\mathbf{3 5}$} & \multicolumn{2}{c}{$\boldsymbol{x}=\mathbf{6 5}$} \\
\cline { 2 - 7 } & Male & Female & Male & Female & Male & Female \\
\hline 2020 & 9.69645 & 9.7114346 & 9.6676104 & 9.6807541 & 8.8198747 & 9.1051825 \\
\hline 2021 & 9.696601 & 9.711794 & 9.669064 & 9.682219 & 8.82517 & 9.113787 \\
\hline 2022 & 9.696751 & 9.712154 & 9.670518 & 9.683683 & 8.830466 & 9.122394 \\
\hline 2023 & 9.696902 & 9.712513 & 9.671972 & 9.685148 & 8.835763 & 9.131004 \\
\hline 2024 & 9.697052 & 9.712873 & 9.673425 & 9.686613 & 8.841061 & 9.139616 \\
\hline
\end{tabular}

Regarding to Table 2, it can be seen that the EPV of the annuity for women is higher than for those in men. It could be the case since the probabilities of life for Indonesian's women at those age are higher compared to the probabilities of life for men at the same age. Therefore, we can state that the risk of longevity for the female population in Indonesia is greater than for the male counterparts. In addition, it can be also seen that the EPV of term-life annuity decreases in value with the age of the policyholder. This is understandable because someone, who is older, has a higher probability of death than the youngsters, as shown as in Figure 3.

Figure 3 illustrates an increase in the value of EPV of term-life annuities from 2020 to 2024. This is due to the possibility of a decrease in the probability of death of Indonesian population. Consequently, the EPV of the annuity will be higher. In addition, since the mortality rates of Indonesian's population indicated a downward trend for the last few years, it is likely that there will be a decrease in the probabilties of death among Indonesian in the future. It is interesting to note that if the EPV of this annuity is used in the calculation of premiums and benefits reserves of an insurance product, then the value of the premiums and the benefits reserves should be adjusted annually.



(a)

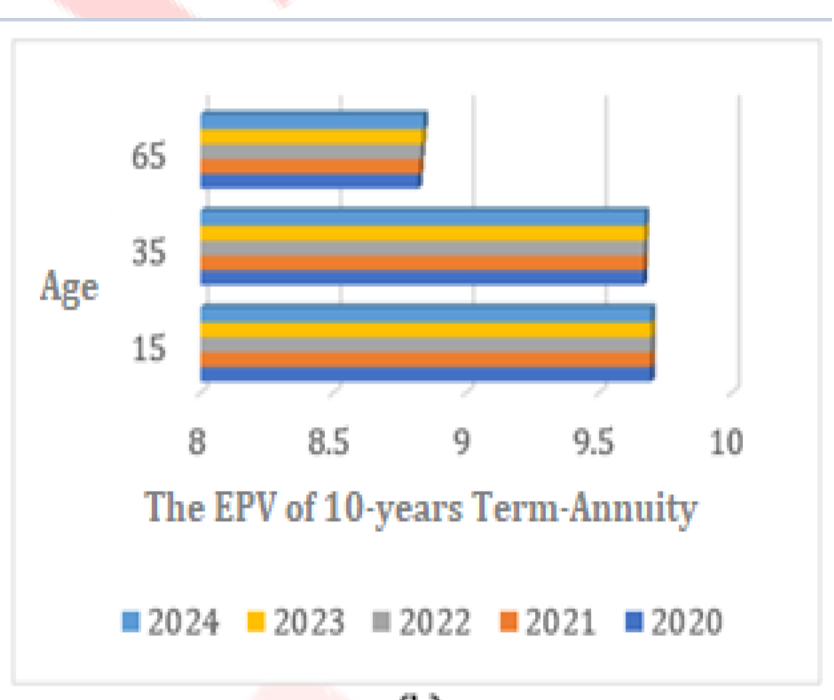

(b)

Figure 3. The EPV of 10 Year Term Life Annuity for (a) Male and (b) Female

In the next case, we calculated the EPV of a term-life annuity payable 1 unit at every beginning of the year where $n=15$-year period for people aged 15,35 , and 65 , respectively. The results of this calculation by using the UDD assumption can be seen on Table 3. 
Table 3. EPV of Term Life Annuity Paid 1 at Every Beginning of the Year $\left(\ddot{a}_{x: \bar{n}}\right)$ with $n=15$

\begin{tabular}{ccccccc}
\hline \multirow{2}{*}{ Year } & \multicolumn{6}{c}{$\ddot{\boldsymbol{a}}_{\boldsymbol{x}: \overline{\boldsymbol{n}} \mid}$} \\
\cline { 2 - 7 } & \multicolumn{2}{c}{$\boldsymbol{x}=\mathbf{1 5}$} & \multicolumn{2}{c}{$\boldsymbol{x}=\mathbf{3 5}$} & \multicolumn{2}{c}{$\boldsymbol{x}=\mathbf{6 5}$} \\
\cline { 2 - 7 } & Male & Female & Male & Female & Male & Female \\
\hline 2020 & 14.158373 & 14.202531 & 14.061289 & 14.100742 & 11.622331 & 12.34773 \\
\hline 2021 & 14.15915 & 14.20381 & 14.06548 & 14.10486 & 11.63473 & 12.37188 \\
\hline 2022 & 14.15993 & 14.20509 & 14.06967 & 14.10897 & 11.64714 & 12.39608 \\
\hline 2023 & 14.16071 & 14.20638 & 14.07387 & 14.11309 & 11.65956 & 12.42032 \\
\hline 2024 & 14.16149 & 14.20766 & 14.07806 & 14.11721 & 11.672 & 12.44459 \\
\hline
\end{tabular}

In the third case, we calculate the EPV of a term-life anuuity due for $n=20$-year period by using the same data and assumptions. The results of this calculation can be seen on Table 4 .

Table 4. EPV of Term Life Annuity Paid 1 at Every Beginning of the Year $\left(\ddot{a}_{x: \bar{n} \mid}\right)$ with $n=20$

\begin{tabular}{ccccccc}
\hline \multirow{2}{*}{ Year } & \multicolumn{7}{c}{$\ddot{\boldsymbol{a}}_{\boldsymbol{x}: \bar{n} \boldsymbol{|}}$} \\
\cline { 2 - 7 } & \multicolumn{2}{c}{$\boldsymbol{x}=\mathbf{1 5}$} & \multicolumn{2}{c}{$\boldsymbol{x}=\mathbf{3 5}$} & \multicolumn{2}{c}{$\boldsymbol{x}=\mathbf{6 5}$} \\
\cline { 2 - 7 } & Male & Female & Male & Female & Male & Female \\
\hline 2020 & 18.379885 & 18.462734 & 18.135935 & 18.223402 & 13.36043 & 14.556865 \\
\hline 2021 & 18.38197 & 18.46565 & 18.14439 & 18.23149 & 13.37991 & 14.60024 \\
\hline 2022 & 18.38405 & 18.46857 & 18.15285 & 18.23958 & 13.39942 & 14.64378 \\
\hline 2023 & 18.38613 & 18.47149 & 18.16132 & 18.24767 & 13.41895 & 14.68746 \\
\hline 2024 & 18.38821 & 18.47441 & 18.16979 & 18.25577 & 13.43852 & 14.73129 \\
\hline
\end{tabular}

If we make an observation in a period of time, for example we focus on the EPV of annuities in 2021, then we find that there is a relatively big difference in the value of EPV of the annuities for both each age group and each sex. This finding can be seen in Figure 4 and Figure 5.

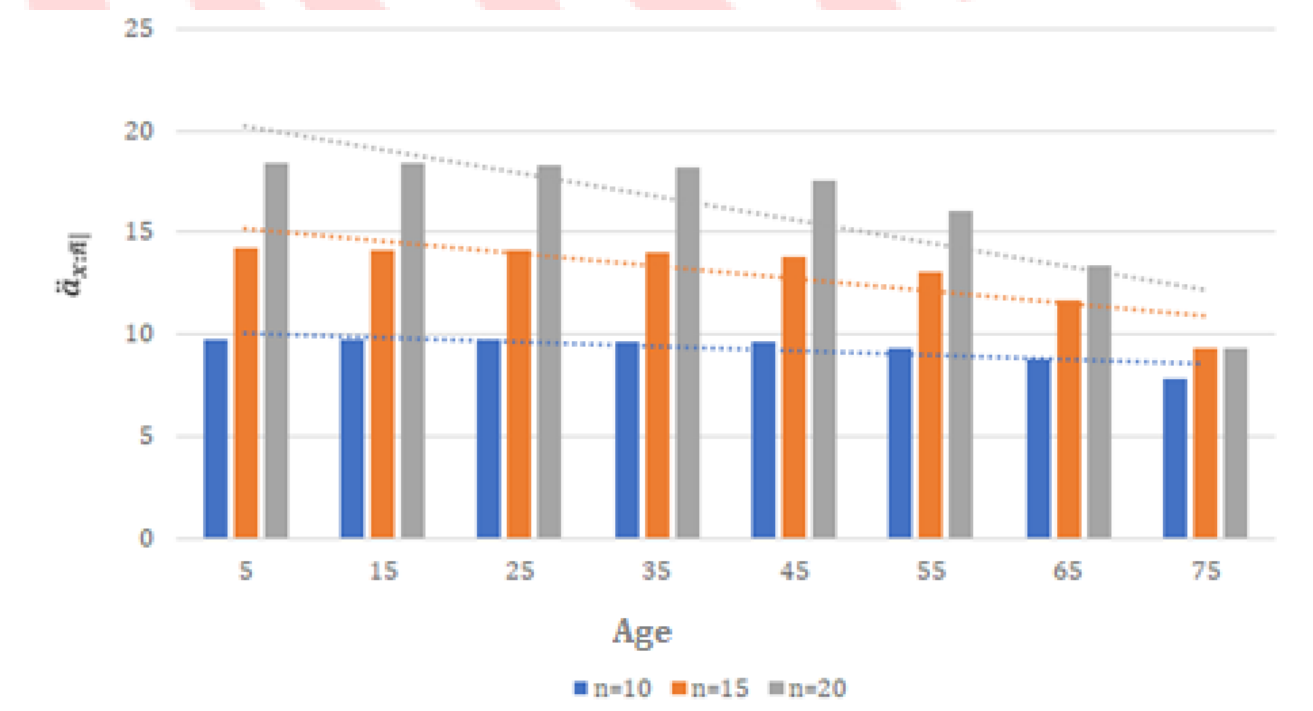

Figure 4. Projected EPV of Term-Life Annuity Due in 2021 for Male Indonesian Population

Figure 4 depicts the projected EPV of term-life annuity for male Indonesian population. It can clearly be seen that the EPV value decreases with age. In addition, the same trend is also be found in the calculations of the EPV of annuity for the three different periods, namely for $n=10, n=15$, and $n=20$. 


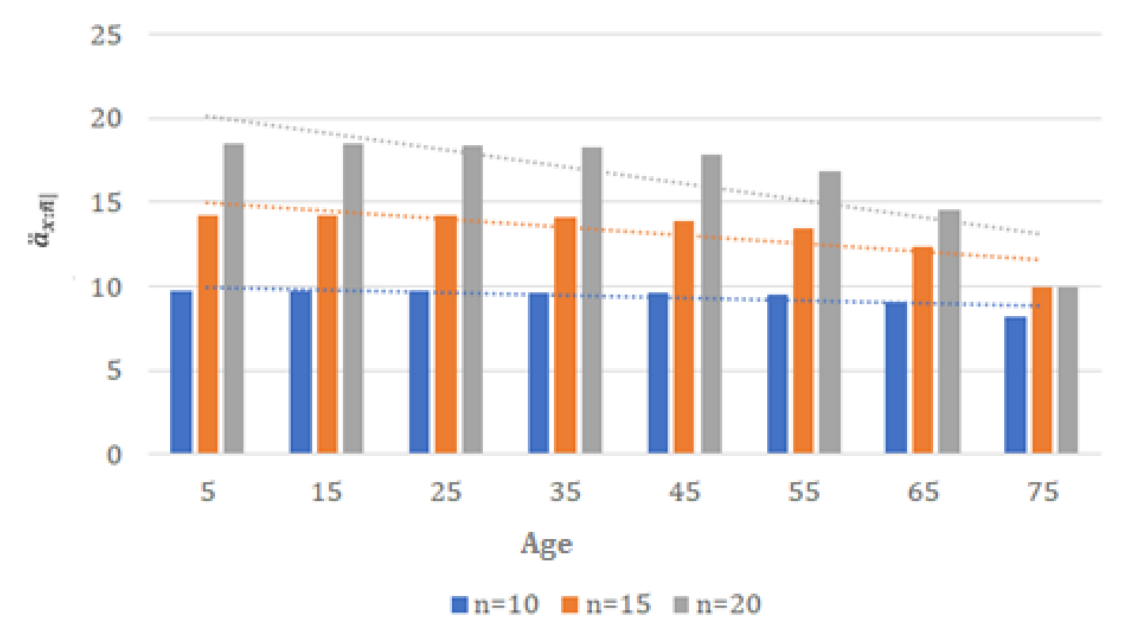

Figure 5. Projected EPV of Term-Life Annuity Due in 2021 for Female Indonesian Population

The similar result is also be found in the female population. One can see, from figure 5, that the EPV of term-life annuity will increase with the periods. However, this EPV will decline with the age. It can be the case because when the period of an annuity is longer, then the amount of funds to be paid in the annuity will be greater. On the other hand, the increasing age will lead to smaller EPV of term-life annuities, since the older age group indicates smaller probabilities of life. Thus, if the life-annuity is assumed to be a premium paid by the policy holder, the premium payment will not be paid until the end of the period because the policyholder tends to die while the policy was still active.

A study of mortality in line with its characteristics and its forecasts can enable a country to understand the dynamics of its population. Phenomena such as a population growth and a decreasing mortality rates are very interesting topic, since it has a great relationship with the economic and social impacts.

\section{E. CONCLUSION AND SUGGESTION}

Based on the projection for the next 5-year period of Abridged Life Table in Indonesian population, we noted that there is a possibility of a decrease in the probabilities of death for both sexes. This finding suggests that there is a potential increase of longevity risk in the future for some insurance contracts, especially for life annuties. It can be seen from the calculation of the EPV of term-life annuities which indicate a substantial increase every year. If the annuity represents the benefits that must be paid by the insurance company to the policyholders, then the company may suffer a significant loss if it does not use the updated probabilities of death's data. Furthermore, the projected data that we proposed can also be used by the government as well as insurers in determining the policies in the future.

However, we also noticed that the Abridged Life Table data had some drawbacks. First, there was a lack of information at each age group because the given data was the probabilities of a person who was still alive at the start of the interval, and then died at a given age interval. Second, the UDD assumption, which was used in the calculation of the EPV of the annuity, was not always true in the real situation. Therefore, in order to increase the accuracy of the calculation, we suggest that the further research should consider the other assumptions in calculating the probabilities of death as well as the EPV of the annuity.

\section{REFERENCES}

AAJI. (2019). E-Book Tabel Mortalitas Indonesia IV. Asosiasi Asuransi Jiwa Indonesia (AAJI).

Bacinello, A. R., Chen, A., Sehner, T., \& Millossovich, P. (2021). On the market-consistent valuation of participating life insurance heterogeneous contracts under longevity risk. Risks, 9(1), 1-18. https://doi.org/10.3390/risks9010020

Burch, T. K. (2018). Model-Based Demography. In Demographic Research Monographs (Vol. 9, Issue 429). http://link.springer.com/10.1007/978-3-319-65433-1

Chang, Y., \& Sherris, M. (2018). Longevity risk management and the development of a value-based longevity index. Risks, 6(1). https://doi.org/10.3390/risks6010010

Coloma, G., \& Date, M. C. (2020). HUMAN MORTALITY EFFECTS OF ECONOMIC of Austrian population based on 1960- 
2017 data. May.

Diaz, G., Debón, A., \& Giner-Bosch, V. (2018). Mortality forecasting in Colombia from abridged life tables by sex. Genus, 74(1). https://doi.org/10.1186/s41118-018-0038-6

Dickson, D., Hardy, M., \& Waters, H. (2009). Actuarial Mathematics for Life Contingent Risk. Cambridge University Press.

Dmitriev, Y. G., Gubina, O. V, \& Koshkin, G. M. (2019). Applied Methods of Statistical Analysis. Statistical Computation and Simulation. Proceedings of the International Workshop, September, 195.

Ibrahim, R. I., \& Siri, Z. (2011). Methods of expanding an abridged life tables: Comparison between two methods. Sains Malaysiana, 40(12), 1449-1453.

Janssen, F. (2018). Advances in mortality forecasting: introduction. Genus, 74(1). https://doi.org/10.1186/s41118-0180045-7

Koshkin, G. M., \& Gubina, O. V. (2016). Estimation of the present values of life annuities for the different actuarial models. Proceedings - 2nd International Symposium on Stochastic Models in Reliability Engineering, Life Science, and Operations Management, SMRLO 2016, 506-510. https://doi.org/10.1109/SMRL0.2016.89

Li, J. S. H., Zhou, R., \& Hardy, M. (2015). A step-by-step guide to building two-population stochastic mortality models. Insurance: Mathematics and Economics, 63, 121-134. https://doi.org/10.1016/j.insmatheco.2015.03.021

Pavlov, V., \& Mihova, V. (2018). An application of survival model in insurance. AIP Conference Proceedings, 2025(October). https://doi.org/10.1063/1.5064883

Zhu, X., Hardy, M., \& Saunders, D. (2018). Valuation of an early exercise defined benefit underpin hybrid pension. Scandinavian Actuarial Journal, 2018(9), 823-844. https://doi.org/10.1080/03461238.2018.1463556 
168 | Jurnal Varian| Vol. 4, No. 2, April 2021, Hal. 159-168 